ББК 63.4

$$
\begin{gathered}
\text { Организация конференции и издание материалов проведены } \\
\text { при финансовой поддержке Российского фонда фундаментальных исследований, } \\
\text { проект № 19-09-20008 }
\end{gathered}
$$

Утверждено к печати Ученым советом ИИМК РАН

Редакционная коллегия тома II: А. В. Поляков, Е. С. Ткач (отв. редакторы), М. Т. Кашуба, Л. Б. Кирчо, Е. А. Черлёнок, В. Я. Стёганцева, А. И. Климушина

Рещензенты: д. и. н. Л. Б. Вишняцкий, д. и. н. А. А. Выборнов

Программный комитет конференции: академик РАН, д. и. н., проф. М. Б. Пиотровский (Государственный Эрмитаж, почетный председатель); д. и. н. В. А. Лапшин (ИИМК РАН, председатель); д. и. н. А. В. Головнёв (МАЭ РАН, сопредседатель); д. и. н. В. А. Дергачёв (Высшая антропологическая школа, Молдова, сопредседатель); д. и. н. И. Ф. Попова (ИВР РАН, сопредседатель); академик АН Республики Узбекистан, д. и. н., проф. Э. В. Ртвеладзе (сопредседатель); к. и. н. А. В. Поляков (ИИМК РАН, зам. председателя); к. и. н. В. А. Алёкшин (ИИМК РАН, зам. председателя); д. и. н. Ю. Е. Берёзкин (МАЭ РАН); Dr., Prof. Н. Бороффка

(Германский археологический институт, Германия); В. С. Бочкарёв (ИИМК РАН);

Dr. Э. Кайзер (Свободный университет Берлина, Германия); к. и. н. М. Т. Кашуба (ИИМК РАН); д. и. н. Л. Б. Кирчо (ИИМК РАН); к. и. н. А. В. Кияшко (Южный федеральный университет); к. и. н. П. Ф. Кузнецов (СГСПУ); к. и. н. Н. М. Малов (СНИГУ); к. и. н. В. П. Никоноров (ИИМК РАН); Ю. Ю. Пиотровский (Государственный Эрмитаж); д. и. н., проф. Д. Г. Савинов (Институт истории СПбГУ); к. и. н. В. Н. Седых (Институт истории СПбГУ); к. и. н. Н. Н. Скакун (ИИМК РАН); к. и. н. Н. Ф. Соловьёва (ИИМК РАН); к. и. н. А. И. Торгоев (Государственный Эрмитаж); к. и. н. Е. А. Черлёнок (Институт истории СПбГУ)

Организационный комитет конференции: к. и. н. А. В. Поляков (ИИМК РАН, председатель); к. и. н. В. А. Алёкшин (ИИМК РАН, зам. председателя); В. С. Бочкарёв (ИИМК РАН); к. и. н. М. Т. Кашуба (ИИМК РАН); д. и. н. Л. Б. Кирчо (ИИМК РАН);

А. И. Климушина (ИИМК РАН, отв. секретарь); к. и. н. В. П. Никоноров (ИИМК РАН); Ю. Ю. Пиотровский (Государственный Эрмитаж); В. Я. Стеганцева (ИИМК РАН); В. В. Терёхина (ИИМК РАН, МАЭ РАН, отв. секретарь); к. и. н. Е. С. Ткач (ИИМК РАН); И. Ж. Тутаева (Государственный Эрмитаж); к. и. н. Е. А. Черлёнок (Институт истории СПбГУ)

Древности Восточной Европы, Центральной Азии и Южной Сибири в контексте связей и взаимодействий в евразийском культурном пространстве (новые данные и концепции): Материалы Международной конференции, 18-22 ноября 2019 г., Санкт-Петербург. Т. ІІ. Связи, контакты и взаимодействия древних культур Северной Евразии и цивилизаций Востока в эпоху палеометалла (IV-I тыс. до н. э.). К 80-летию со дня рождения выдающегося археолога В. С. Бочкарёва. - СПб.: ИИМК РАН, Невская Типография, 2019. - 287 с.

ISBN 978-5-907053-35-9

DOI 10.31600/978-5-907053-35-9 
или обсечения облоя на серпах не обнаружено, во всех случаях постлитейной обработки литьевые дефекты прокованы к поверхности клинка.

Проковка лезвия качественных серпов перед использованием и применение укрепленной ковкой бракованной заготовки демонстрирует преобладание этой технологии среди методов постлитейной обработки металла в мастерской, изготовившей данный клад, а также сознательное использования ковки мастерами не просто для придания нужной формы изделию, а, в первую очередь, для улучшения механических свойств предметов.

\section{Литература}

Аванесова Н. А. 1991. Культура пастушеских племен эпохи бронзы Азиатской части СССР. Ташкент.

Дергачёв В. А., Бочкарёв В. С. 2002. Металлические серпы поздней бронзы Восточной Европы. Кишинёв.

Черных Е. Н. 1966. О химическом составе металла клада из Сосновой Мазы // КСИА. Вып. 108. C. $123-131$.

\section{USE-WEAR ANALYSIS OF “SICKLES” FROM THE SOSNOVAYA MAZA HOARD}

Anastasiya Yu. Loboda ${ }^{\star}$, Natal'ya I. Shishlina $^{\star *}$

${ }^{\star}$ Kurchatov Institute, Moscow, Russia; ${ }^{* *}$ State Historical museum, Moscow, Russia

Keywords: Sosnovaya Maza hoard, tracewear analysis.

Use-wear analysis of "sickles" from the Sosnovaya Maza hoard revealed traces on the surface of these objects that were assigned to three technological stages of their life histories. Casting defects (caverns, excrescences, porosity) belong to the stage of casting of the products. Forging of the blade, burrs and casting defects, grinding of the blade are traces of post-processing. A third group of traces has also been distinguished reflecting probably the stage of the use of the sickles: notches on the blades, cracks, in one case, traces of cutting of the blade. The working of the sickles after casting is better observable on objects with minor casting defects; however, a number of exceptions were recorded. The forging of high-quality sickle blades before their use and the employment of reinforcing forging of defective blanks demonstrates the predominance of this technique over the other methods of post-casting metal processing in the workshop where the objects from this hoard were manufactured. Also the intentional use of forging, not in order just to shape the desired product, but, primarily, to improve its mechanical properties is observable.

\section{ОБ ОДНОМ ТИПЕ МЕТАЛЛИЧЕСКИХ КИНЖАЛОВ ЭПОХИ ПОЗДНЕЙ БРОНЗЫ - РАННЕГО ЖЕЛЕЗА СЕВЕРО-ВОСТОЧНОГО КАВКАЗА}

\section{О. В. Сычёва}

Институт истории материальной культуры РАН, Санкт-Петербург, Россия

DOI: 10.31600/978-5-907053-35-9-196-198

Ключевые слова: бронзовый век, бронзовые кинжалы, Ярык-су, Дагестан, оружие, кобанская культура, Сержень-Юрт.

В могильниках Северо-Восточного Кавказа, которые датируются временем перехода от ПБВ к РЖВ, были найдены своеобразные кинжалы, которые по целому ряду признаков отличаются от кинжалов кобанской культуры. Недавно серия этих кинжалов пополнилась за счет находки с берега р. Ярык-су близ сел. Симсир, Казбековского р-на Республики Дагестан (на границе с Ножай-Юртовским р-ном Республики Чечня). 
Коллекция кинжальных клинков с берега р. Ярык-су насчитывает 19 экз. На основании типологического анализа и, в частности, наиболее существенного признака - наличия или отсутствия выделенного черенка, эти кинжалы можно разделить на два типа. К первому mипу относятся кинжалы с треугольным лезвием, небольшим черенком или «язычком» и отверстиями для крепления рукояти (№ 4, 9, 13, 18). Ко второму типу относятся кинжалы без выделенного черенка, которые в свою очередь можно разделить на два варианта. К первому варианту относятся изделия с треугольным клинком, овальным верхом и отверстиями для крепления рукояти (№ 1, 2, 3, 7, 8, 12, 15, 16). Ко второму варианту относятся кинжалы с треугольным клинком, подтреугольным верхом и отверстиями для крепления рукояти (№ 5 , $6,10,11,14,17,19)$. Длина кинжалов составляет 13-21 см. Кинжал № 7 обломан, а кинжал № 8 изначально имел небольшие размеры. Вес клинков колеблется от 23 до 172 г.

Подобные кинжалы встречаются в памятниках Северного и Южного Кавказа. Наиболее близкие аналогии происходят из могильников Зандакский, Эльхотово, Майртупский II, Сержень-Юртовский, Чми и Самтавро. Исходя из датировок аналогичных кинжалов, все представленные клинки могут быть датированы XI-X вв. до н. э. Так, кинжалы из СерженьЮрта В. И. Козенкова относит к рубежу XI-X вв. до н. э. (Козенкова 2002: 89). Аналогично датированы и кинжалы из Майртупского могильника (Виноградов, Дударев 2003: 26), а Е. И. Крупнов относил подобные кинжалы к XII-IX вв. до н. э. (Крупнов 1951: 60).

Анализ состава металла исследуемой серии показал, что кинжалы № 1-5, 10, 14-17 и 19 отлиты из мышьяковой бронзы, а кинжалы № 6-9, 12-13, 19 - из оловянно-мышьяковой бронзы, кинжал № 18 - из оловянной бронзы, а в металле кинжала № 11 примесь мышьяка составляет $<0,9$ \%. Для Центрального Кавказа, территории распространения кобанской культуры позднего бронзового века, характерными являются оловянные сплавы. Количество олова в сплавах варьирует от 2 до $10 \%$. В качестве приплава преобладает сурьма, тогда как в более раннее время преобладает приплав мышьяка (Техов 1991: 228).

Классические кинжалы Кобани можно разделить на два класса - с цельнолитой рукоятью и без нее. К кинжалам без цельнолитой рукояти относятся несколько типов. Наиболее распространенными являются клинки с S-видным лезвием, небольшим овальным черенком, отверстиями для крепления рукояти и нервюрой. К кинжалам с цельнолитой рукоятью относятся клинки треугольной формы с черенком, имеющим вид уступа и отверстиями для крепления рукояти (или без таковых). Состав металла, форма клинка и наличие срединного ребра отличают эти клинки от клинков с Ярык-су. Клинки, аналогичные клинкам с Ярык-су, в Тлийском могильнике встречены только в трех погребениях (№ 12, 32, 207) (Техов 1980: 11, 14, 18).

Таким образом, рассматриваемые нами кинжалы являются особым типом, который представлен в так называемом восточном варианте кобанской культуры. В действительности же этот вариант является самостоятельной, отличной от кобанской, археологической культурой. Об этом говорит и своеобразная керамика из могильников Восточного Кавказа, которая резко отличается от собственно кобанской посуды и имеет ближайшие параллели в каякентско-хорочоевской керамике предшествующего времени. Значительные отличия в погребальном обряде и составе инвентаря восточного и центрального вариантов кобанской культуры позволяют говорить о выделении восточного варианта в отдельную культуру и назвать ее сержень-юртовской.

\section{Литература}

Виноградов В. Б., Дударев С. Л. 2003. Могильники позднего бронзового века у сел. Майртуп в Чечне // Дудаев С. Л. (ред.). Материалы и исследования по археологии Северного Кавказа. Армавир. Вып. 1. С. 5-61. 
Козенкова В. И. 2002. У истоков горского менталитета. Могильник эпохи поздней бронзы раннего железа у аула Сержень-Юрт, Чечня. М. (Материалы по исследованию историкокультурного наследия Северного Кавказа. Вып. 3).

Крупнов Е. И. 1951. Материалы по археологии Северной Осетии докобанского периода (Опыт периодизации памятников эпохи энеолита и бронзы). М. (МИА. № 23).

Техов Б. В. 1980. Тлийский могильник (комплексы XVI-X вв. до н. э.). Тбилиси.

Техов Б. В. 1991. Кавказ в системе палеометаллических культур Евразии // Пицхелаури К. (ред.). О древней металлургии и металлообработке Центрального Кавказа. Тбилиси. C. 224-253.

\title{
ONE TYPE OF LATE BRONZE - EARLY IRON AGE METAL DAGGERS FROM THE NORTH-EASTERN CAUCASUS
}

Ol'ga V. Sycheva

Institute for the History of Material Culture RAS, St. Petersburg, Russia

Keywords: Bronze Age, bronze daggers, Yaryksu, Dagestan, weapons, Koban culture, Serzhen-Yurt.

The paper considers the daggers found in burial grounds dated to the late $2^{\text {nd }}-$ early $1^{\text {st }}$ millennium BC in the territory of the North-Eastern Caucasus. These daggers differ from the classic daggers of the Koban culture. Recently, a series of the daggers under consideration was supplemented with new examples from the region of the Yaryksu River, Republic of Dagestan. This report presents the results of typological and chemical analysis of daggers and highlights the features of the Eastern variant of the Koban culture. The data discussed allow the author to distinguish a specific Serzhen-Yurt culture.

\section{БРОНЗОВЫЙ КОТЕЛ ИЗ СЕЛ. ИВАНОВСКОГО И ДЕРЕВЯННАЯ ПОСУДА С БРОНЗОВЫМИ УШКАМИ ${ }^{1}$}

\author{
Л. С. Ильюков \\ Южный научный иентр РАН, Ростов-на-Дону, Россия
}

DOI: 10.31600/978-5-907053-35-9-198-200

Ключевые слова: поздняя бронза, клепаный бронзовый котел, деревянная посуда.

В. С. Бочкарёв обладает удивительной прозорливостью в изучении больших и ярких категорий источников, которые являются хроноиндикаторами бронзового века. К их числу относится и бронзовая посуда. В 1972 г. он опубликовал интересную статью о киммерийских казанах (Бочкарёв 1972). Спустя тридцать лет, в 2008 г., он вновь обращается к этой теме и вносит в нее ряд существенных правок. В 2010 г. им был издан расширенный текст доклада о металлических котлах эпохи поздней бронзы Восточной Европы (Бочкарёв 2010).

Среди клепаных котлов особое место занимает находка из сел. Ивановского, найденная в 1878 г. С ней был обнаружен еще один котел, но меньших размеров, который не сохранился. По классификации В. С. Бочкарёва, ивановский котел входит во II группу, для которой характерно округлое дно с поддоном и пара литых кольцевидных ручек, стоящих

\footnotetext{
${ }^{1}$ Статья подготовлена в рамках выполнения государственного задания ЮНЦ РАН на 2019 г. по теме «Изучение межкультурных взаимодействий населения Нижнего Дона с древнейших времен до нового времени» (№ госрегистрации АААА-А19-119011190181-1).
} 